\title{
Freshwater Snails Infection Status and Predisposing Risk Factors to Schistosomiasis in Doma Local Government Area, Nasarawa State, Nigeria
}

\author{
Pam VA*, Daramola OS, Uzoigwe NR, Ombugadu A, Maikenti JI, Ahmed HO, Aimankhu PO, Aliyu \\ AA, Ayuba So, Odey SA, Anyebe GE, Adejoh VA, Attah AS and Dogo KS
}

Department of Zoology, Faculty of Science, Federal University of Lafia, Nasarawa State, Nigeria.

*Corresponding author: Pam VA, Department of Zoology, Faculty of Science, Federal University of Lafia, Lafia, Nasarawa State, Nigeria, E-mail: vicpam2004@gmail.com

\section{ARTICLE INFO}

Received: 幽 July 01, 2021

Published: 幽 July 14, 2021

Citation: Pam VA*, Daramola OS, Uzoigwe NR, Ombugadu A, Maikenti JI, et al., Freshwater Snails Infection Status and Predisposing Risk Factors to Schistosomiasis in Doma Local Government Area, Nasarawa State, Nigeria. Biomed J Sci \& Tech Res 37(2)-2021. BJSTR. MS.ID.005963.

Keywords: Freshwater snails; Cercaria infection; Schistosomiasis predisposing risk factors; Doma LGA

\begin{abstract}
The transmission of trematode parasites is actively aided by snail intermediate hosts. Therefore, this study investigated 17 water bodies in Doma LGA, Nasarawa State, Nigeria for Snails intermediate host as well as the factors that predisposes the communities to schistosomiasis infection in the area between August and October, 2019. The water bodies were visited weekly in the morning hours for the collection of snails using hand-held scooping net as well as handpicking from vegetation around for a period of 30 minutes and then taken to the laboratory for sorting and further processing. The snails were morphologically identified and screened for cercaria infection by exposure to sunlight for 2 hours in a petri-dish that contains distilled water and also crushing and microscopically checking for cercaria. A well-structured questionnaire was administered to members of the communities around the studied water bodies in order to collect data relating to the risk factors that predisposes the community to schistosomiasis. A total of 308 snails were collected from the water bodies which spread across five different species of snails: Bulinus globosus, Bulinus forskalii, Biomphalaria pfeifferi, Lymnae natalensis and Melanoides tuberculata. The predominant snail species was B. globosus. Therefore, the abundance between snail species collected at Doma LGA showed a very high significant difference $(\chi 2=312.03, \mathrm{df}=4, \mathrm{P}<0.0001)$. Zero prevalence of cercaria was observed in the snails. The knowledge level of the people is relatively poor since most of the respondents $211(41.4 \%)$ had contact with contaminated water and 102 (33\%) of them drink unsafe water. A good number of the respondent's source for water source from the tap $313(61.4 \%)$. Majority of the respondents $233(45.7 \%)$ make use of pit laterine in their homes and most of them stay in close proximity to water bodies $326(63.9 \%)$. About half of the respondents $210(41.2 \%)$ have contact with water bodies once a week and at most time in the morning hours $164(32.2 \%)$ for the purpose of washing/laundry 189 (37.1\%). About 40\% of them had experienced blood in their urine in the time past. Only 122 (23.9\%) of the respondents had previously been treated for schistosomiasis, while an ample number of the respondents 388 (76.1\%) have never been treated for the disease and as such are unaware of their status. In conclusion, the absence of cercaria infection in the snails which are known intermediate hosts of causative agents of schistosomiasis suggests that communities in the study area are presently not at risk of schistosomiasis. Observation from responses indicated that the communities maintain a good level of hygienic condition which have militated against the spread of the disease making the site non-endemic to schistosomiasis. Thus, the sanitation lifestyle by the people in the area should be sustained.
\end{abstract}




\section{Introduction}

Schistosomiasis is also referred to as snail fever or bilharziasis. It is a tropical parasitic disease caused by schistosome (blood fluke) [1-4]. The disease is known to be endemic in many countries especially in West Africa [5]. Reports by the World Health Organization (WHO) estimated 243 million people in 52 countries require treatment against the disease [6]. Nigeria has the heaviest burden of the disease in sub-Saharan Africa, with a total of 29 million cases [7]. The transmission of the disease is correlated with freshwater snail intermediate host and requires human contact with the parasite infective stage found in contaminated freshwater bodies. Therefore, communities that live close to snail infested water bodies are mostly at risk of schistosomiasis [8]. Several factors such as social, cultural, environmental and behavioural are known to have direct influence on the prevalence and intensity of schistosomiasis. The role played by various epidemiological factors in the transmission and intensity of the infection has been studied widely using different methods. Distance from the transmission site, migration and emergence of new foci, urbanization, socioeconomic status, sanitation, water supply patterns and disposal of human wastes (faeces and urine) are among the epidemiological factors [9]. Hence, this study investigated freshwater snails intermediary status and risk factors of schistosomiasis in Doma Local Government Area (LGA) of Nasarawa State, Nigeria.

\section{Materials and Methods}

\section{Study Area}

The study was carried out in Doma LGA in Nasarawa state, Nigeria. Doma has an area of $2,714 \mathrm{~km}^{2}$ and had a population of 139,607 in the 2006 census. Its geographical coordinate is $8.4009^{\circ}$ $\mathrm{N}$ and $8.3581^{\circ}$ E. Agriculture (farming and fishing), craftwork and civil service are the major occupations in Doma. It is located in the Guinea savannah region where they experience rainfall from May to October and cold dry season from the month of November.

\section{Freshwater Snail Collection and Identification}

Freshwater snail search and collection was done from the month of August to October, 2019. Samples were collected weekly from the water bodies according to the method described by Abe et al. [10]. A hand-held scoop net (18cm and $0.2 \mathrm{~mm}$ mesh) was used for collecting/scooping and also hand-picking was also employed along the length of the waterbodies at various sites for 30 minutes. Each sampling site was visited in the morning for snail search and collection. Snails collected were put in specimen bottles containing water and then labelled before being transported to the
Department of Zoology laboratory at the Federal University of Lafia. In the laboratory, the snails were washed with water to remove dirt and identified using standard keys by Brown and Christensen [11] and Danish Bilharziasis Laboratory (DBL) [12].

\section{Screening for Cercaria Infection in Snails}

Collected snails were put individually in petri dishes containing distilled water. They were then covered with net to prevent the snails from crawling out of the container. The petri dishes containing the snails were then exposed to light for 2 hours to induce shedding of cercaria if present [13]. Where no cercaria was shed, the snails were gently crushed in a container containing distilled water. The fleshy part of each snail was dissected and examined microscopically for unshed cercaria and rediae [14].

\section{Questionnaire Administration}

A well-structured questionnaire was administered to people seen around the water bodies, in order to collect data relating to their occupation, water contact activities, environmental sanitation, living conditions (like type of water supply, toilets, presence of domestic animals) and health conditions (blood in urine). The individuals involved were those who are resident around the studied water sources. The respondents were both males and females as well as both young and adults.

\section{Data Analysis}

Data obtained was analyzed using $\mathrm{R}$ Console software (Version 3.6.1). Pearson's Chi-square test was used to compare snails abundance between the species encountered. Descriptive simple percentages was used for the information generated from administered questionnaires. The level of significance was set at $\mathrm{P}$ $<0.05$.

\section{Results}

\section{Composition and Abundance of Snails in Doma LGA, Nasarawa State}

A total of 308 snails were collected from the 17 water bodies sampled which cut across five species: Bulinus globosus, Bulinus forskalii, Biomphalaria pfeifferi, Lymnea natalensis and Melanoides tuberculata as shown in Table 1. B. globosus was the most abundant 182 (59.1\%) snail species encountered followed by Biomphalaria pfeifferi 57 (18.5\%) then Lymnea natalensis 32 (10.4\%) while the least was Melanoides tuberculata 11 (3.6\%). Therefore, the abundance between snail species collected at Doma LGA showed a very high significant difference $\left(\chi^{2}=312.03, \mathrm{df}=4, \mathrm{P}<0.0001\right)$. 
Table 1: Composition and abundance of snails in Doma LGA, Nasarawa State, Nigeria between August and October 2019.

\begin{tabular}{|c|c|}
\hline Snail species & Abundance (\%) \\
\hline Bulinus globosus & $182(59.1)$ \\
\hline Bulinus forskalii & $26(8.4)$ \\
\hline Biomphalaria pfeifferi & $57(18.5)$ \\
\hline Lymnea natalensis & $32(10.4)$ \\
\hline Melanoides tuberculate & $11(3.6)$ \\
\hline Total & 308 \\
\hline
\end{tabular}

\section{Prevalence of Parasites in Vector Snails}

Table 2: Prevalence of parasites in vector snails in relation to two screening techniques.

\begin{tabular}{|c|c|c|c|}
\hline \multicolumn{5}{|c|}{ Techniques } \\
\hline Snail species & No. examined & Sunlight No. Infected (\%) & Crushing No. Infected (\%) \\
\hline Bulinus globosus & 182 & $0(0.0)$ & $0(0.0)$ \\
\hline Bulinus forskalii & 26 & $0(0.0)$ & $0(0.0)$ \\
\hline Biomphalaria pfeifferi & 57 & $0(0.0)$ & $0(0.0)$ \\
\hline Lymnaea natalensis & 32 & $0(0.0)$ & $0(0.0)$ \\
\hline Melanoides tuberculate & 11 & $0(0.0)$ & $0(0.0)$ \\
\hline Total & 308 & $0(0.0)$ & $0(0.0)$ \\
\hline
\end{tabular}

Of the 308 snails examined for parasites using the light and crushing techniques none was found to be infected with trematode cercaria (Table 2).

\section{Socio-demographic Status of Respondents in Relation to Schistosomiasisis Risk Factors}

Out of the 510 questionnaires administered, 383 (75.1\%) were males while females were 127 (24.9\%). More adults 289 (56.7\%) participated than children 221 (43.3\%). Also, the respondents are resident in Doma LGA and familiar with the water bodies sampled. In overall, 225 (44.1\%) of the participants had secondary education, followed by 149 (29.2\%) who had primary education then the uneducated $84(16.5 \%)$ while only $52(10.2 \%)$ of the respondent had a tertiary education. Majority of the respondents were unemployed 231 (45.3\%), self-employed (trade) were 96 (18.2\%), 13 (2.6\%) were civil servants (official), 103 (20.2\%) were farmers, 12 (2.4) were into fishing while those into other forms of commercial activities (driving, construction) were 55 (10.8\%) as shown in Figure 1.

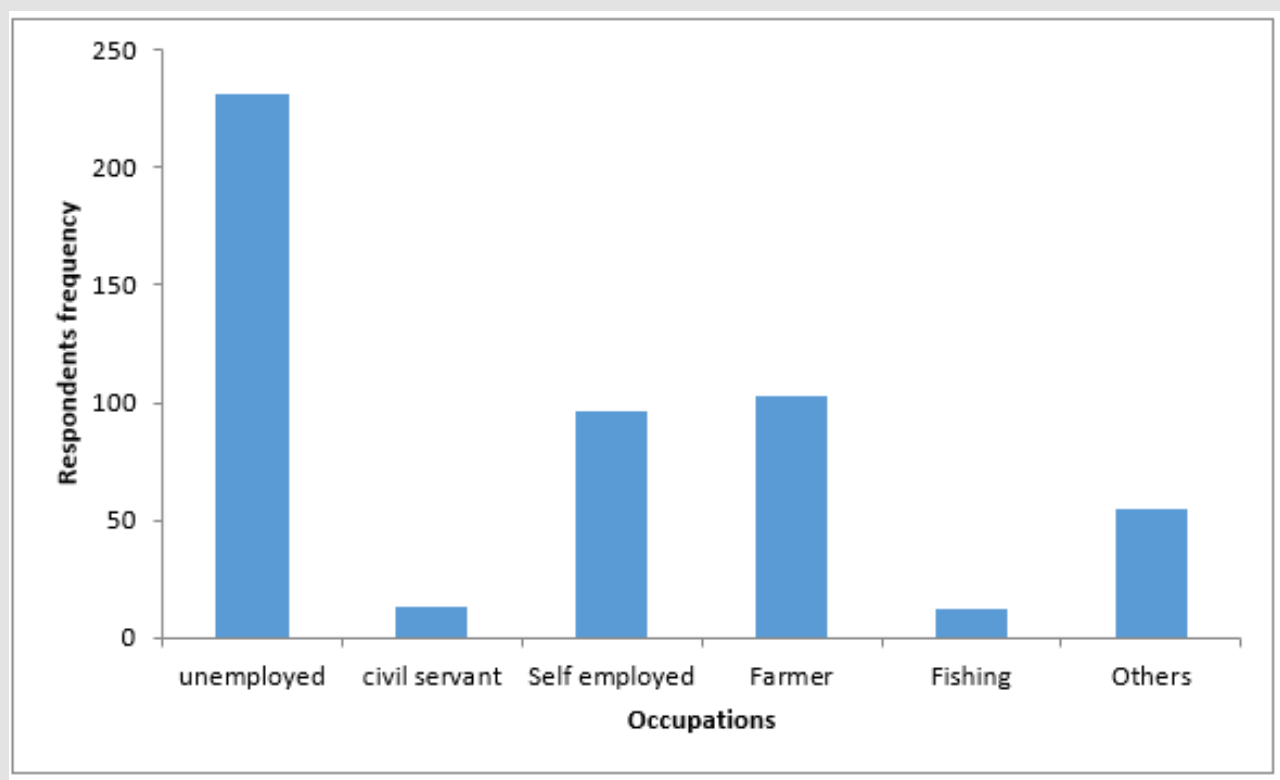

Figure 1: Occupational status of respondent around water bodies in Doma LGA, Nasarawa State, Nigeria. 


\section{Schistosomiasisis Risk Factors}

Information gotten from respondents on their knowledge of the disease showed that 211 (41.4\%) of the participant had contact with contaminated water, $89(17.5 \%)$ and 61 (12\%) respondents wash in surface water and walk without shoe respectively, while 102 drinks unsafe water. A high number of the respondents 232 $(45.5 \%)$ use pipe-borne water for domestic purposes in their homes whereas $87(17.0 \%)$ of them utilized well water as the main source of water for domestic purposes while 191 (37.5\%) accessed water from rivers, streams and pools (Figure 2). Figure 3 showed that pit latrine was the most widely used type of toilet in this study with $233(45.7 \%)$ respondents. 143 (28\%) of the respondents make use of modern flush toilet (water system) in their homes while 76 (14.9\%) respondents utilize other forms of latrine (including the use of buckets, nylons) and $58(11.4 \%)$ in nature (bush).

Figure 2: Proportion of respondents sources of water in the study area: a predisposing schistosomiasisis risk factor.

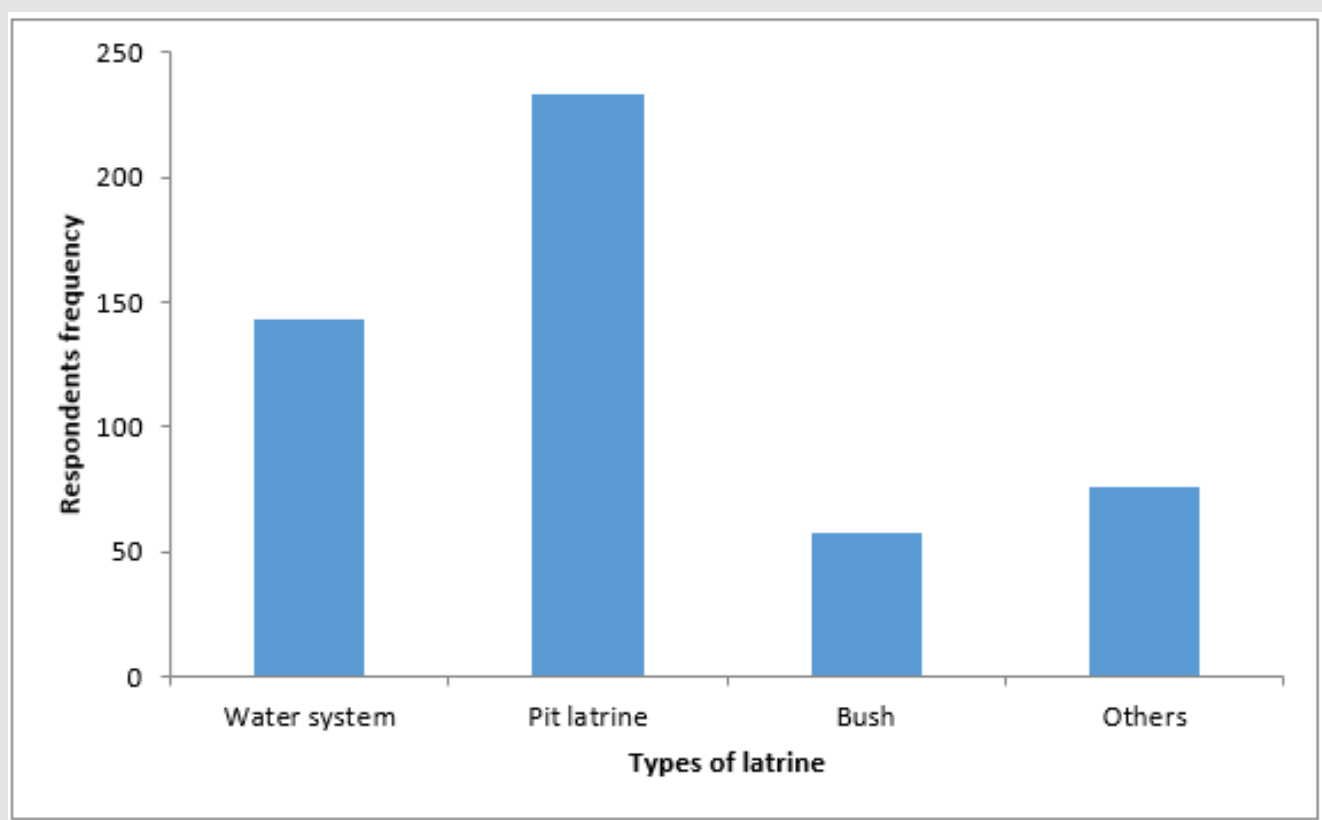

Figure 3: Types of latrine in the study area a predisposing schistosomiasis is risk factor. 
Also, $313(61.4 \%)$ of the respondents had domestic animals present in their homes and 197 (38.6\%) do not. While 326 (63.9\%) of the respondents stay in close proximity to water bodies as compared to $184(36.1 \%)$ who reside at a distance (>250 m) to waterbodies. One hundred and sixty-four (32.2\%) respondents have contact with water mostly in the morning followed by those who have contact with water in the evening 114 (22.4\%) while only a few $41(8 \%)$ have water contact in the afternoon (Figure 4). The frequency of water contact also indicates that $138(27.1 \%)$ respondent come in contact with water bodies daily, 210 (41.2\%) had contact weekly, 118 (23.1\%) had water contact monthly, while 44 (8.6\%) only come in contact with water body at most once or twice in a year. The reasons for water contact varies among respondents, $189(37.1 \%)$ come in contact with water bodies for the purpose of washing/laundry, 97 (19\%) for the purpose of swimming/bathing, 17 (3.3\%) go for fishing, 11 (2.2\%) and 94 (18.4\%) source the water for cooking and gardening/farm purposes, 7 (1.4\%) for the purpose of waste disposal while 95 (18.6\%) come in contact with the water bodies for other reasons.

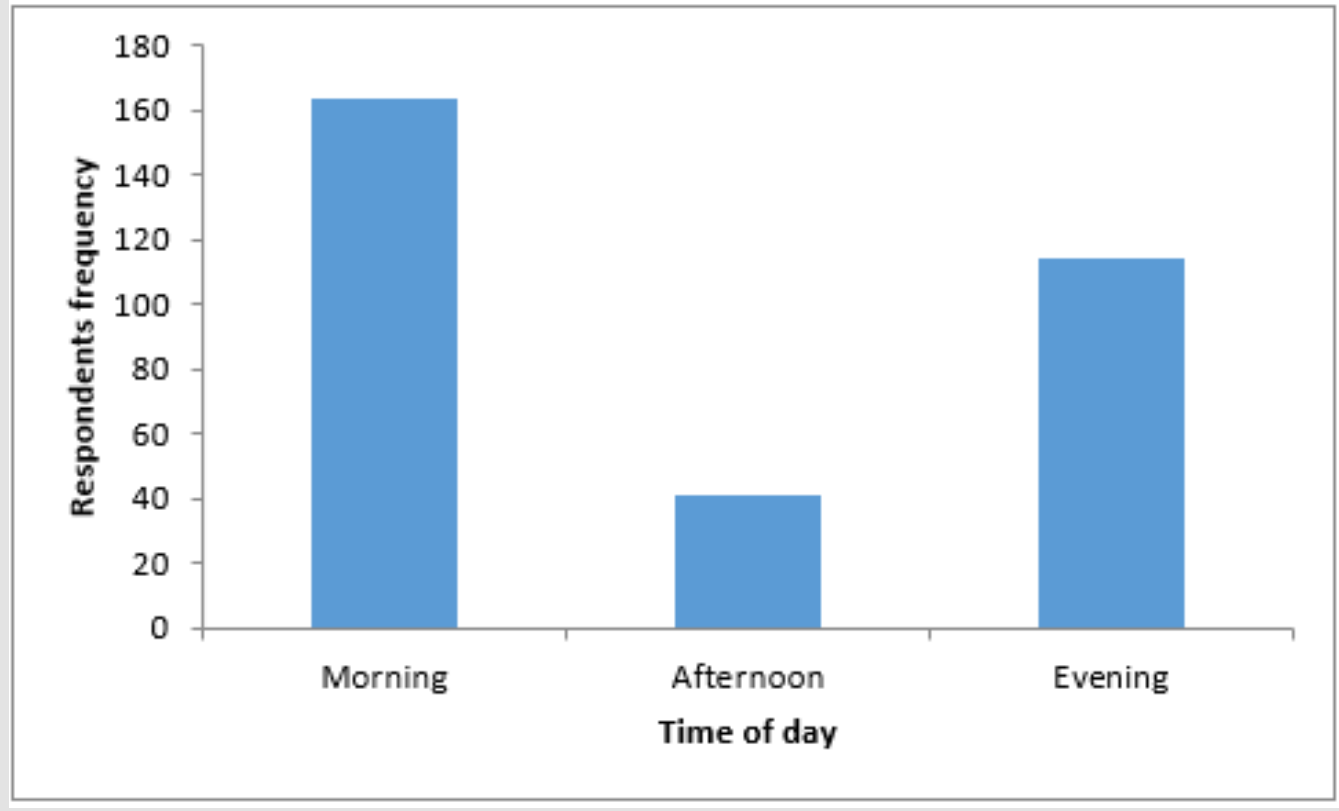

Figure 4: Time of day when respondents have contact with water bodies around.

Blood in urine and bloody stool was experienced by 197 (38.6\%) and 86 (16.9\%) respondents respectively. Also, 227 (44.5\%) have experienced abdominal pain. However, only 122 (23.9\%) of the respondent have previously been treated for schistosomiasis, while an ample number of the respondents 388 (76.1\%) have never been treated for the disease and are unaware of their status.

\section{Discussion}

The snail species reported in this study (Table 1) had earlier been reported in different parts of Nigeria. Omudu and Iyough [15] reported the presence of B. globosus, Lanistes libycus, L. natalensis and Nepa cinerea in Makurdi, Benue State. Similarly, Okafor and Ngang [16] found B. globosus, B. truncatus, B. senegalensis, B. forskalii, Bi. pfeifferi. Lanistes varicus and L. natalensis in their studies in Niger-cem, Nkalagu Eastern Nigeria. Abe et al. [10] studies in almost all Local Government Areas (LGAs) of Nasarawa State showed that snail species were present in all the selected LGAs covered. Interestingly, a species of snail, M. tuberculata found in
Doma was not reported in the study by Abe et al. [10]. Alternatively, Indoplanorbis exutus reported by Abe et al. [10] was absent in Doma LGA. The result of this study is therefore additional information on snail species of medical importance in Nasarawa State which before now has not been documented.

The presence of five freshwater snails in these studies is a clear indication of that the water bodies are potential transmission sites of schistosomiasis and other snail-borne diseases based on observed anthropogenic activities such as fishing, swimming/quick bath by farmers, washing, fetching, watering points for animals and channeling of water for irrigation in the sites. Such activities often result in decrease in the availability of water and could lead to pollution/contamination which affects freshwater snails. This is in tandem with research findings from Okafor and Ngang [16] which gave an update on freshwater snails of medical and veterinary importance and Ugochukwu et al. [9] where they reported higher frequency of schistosomiasis in farmer and fishermen due to their water contact activities. 
The absence of shedded cercaria from the snail could possibly be attributed to good sanitation and hygiene practices in the area, therefore, suggests that human prevalence status in the area should be carried out so as to really ascertain the prevalence rate within the human population. Also, the absence of cercaria infection in the snails implies that schistosomiasis may not be endemic in the study area. This is accordance with the finding of Abe et al. [10] who reported that from 105 sites surveyed, no developing stage of trematodes was observed in 977 snail intermediate host examined. Another study by Rabi [17]in three parts of Jakara dam in Kano State indicated that none of the snails collected was found to be shedding any schistosome cercaria but cyclops was found. Similar observations were also made by Diakité et al. [18] in Cote d'ivoire and Ejehu et al. [19] in Oguta Lake in Nigeria.

Responses from respondents to questions intended to determine the existence of social factors that predisposes the community to schistosomiasis supports the observation made earlier on lack of endemicity of the infection in the area due to the absence of infected snails. Although about $45.5 \%$ of the respondents have access to tap water, however, the contact with snail infested water bodies by about $37 \%$ of the respondents is quite alarming and concurs with Ugochukwu et al. [9] who documented that occupational risk in relation to schistosomiasis arises from water contact. The very low defecation rate $(11.4 \%)$ in bushes and the proper practice of faecal disposal in the area either via the use of water system $(28 \%)$ or pit latrine $(45.7 \%)$ accounts for the absence of schistosomiasis in the area. This is line with Dawaki et al. [2] who reported that one of the factor known to aid endemicity of the disease is good refuse disposal system most especially feaces.

\section{Conclusion}

This study has added to already existing checklist of freshwater snails in Nasarawa State based on the finding of the snail, $M$. tuberculata in Doma LGA. None of the snails' shedded cercaria. Hence, the communities should maintain the good level of hygiene and sanitation thus far recorded in order to perpetually remain free from schistosomiasis infection.

\section{Conflicts of Interest}

None.

\section{References}

1. Nafiu S, Inuwa B, Abdullahi A, Alkali Z, et al. (2016) Prevalence of Urinary Schistosomiasis Among Primary School Pupils in Kofa Primary School, Tafa Local Government, Niger State, Nigeria. Ewemen J. Epidemiol. Clin Med 2(1): 7-13.

2. Dawaki S, Al-Mekhlafi HM, Ithoi I, Ibrahim J, Abdulsalam AM, et al. (2015) The Menace of Schistosomiasis in Nigeria: Knowledge, Attitude, and Practices Regarding Schistosomiasis among Rural Communities in Kano State. PLoS ONE 10(11): e0143667.

3. Ahmad MM, Getso BU, Ahmad UA (2014) Water Contact Patterns and Urinary Schistosomiasis Transmission among School Children in Endemic Area of Wudil, Kano, Nigeria. IOSR J Pharmacy Biol Sci 9(3): 01-04.

4. (2014) WHO. Schistosomiasis. Fact sheet Nº115 12 March 2014.

5. Mbata T, Orji M, Oguoma V (2008) The Prevalence of Urinary Schistosomiasis in Ogbadibo Local Government Area of Benue State, Nigeria. The Internet J Infect Dis 7(1): 1-4.

6. (2012) WHO. Accelerating Work to Overcome the Global Impact of Neglected Tropical Diseases - A Roadmap for Implementation. Geneva, Switzerland: World Health Organization.

7. Hotez PJ, Kamath A (2009) Neglected tropical diseases in sub-Saharan Africa: Review of their prevalence, distribution, and disease burden. PLoS Negl Trop Dis 3(8): e412.

8. Utzinger J, N'Goran EK, Caffrey CR, Keiser J (2011) From innovation to application: social-ecological context, diagnostics, drugs and integrated control of schistosomiasis. Acta Trop 120(1): S121-137.

9. Ugochukwu DO, Onwuliri COE, Osuala FOU, Dozie INS, Opara FN, et al. (2013) Endemicity of schistosomiasis in some parts of Anambra State, Nigeria. J Med Lab Diagn 4(5): 54-61.

10. Abe EM, Ombugadu A, Oluwole AS, Njila HL, Mogaji HO, et al. (2016) Population Abundance and Bionomics of snail intermediate Hosts of Trematodes Parasites in Nasarawa State. Nigeria Research Journal of Parasitology 12(1): 8-18.

11. Brown DS, Kristensen TK (1993) A fish guide to freshwater snails. DK2920, Danish Bilharziasis Laboratory, Charlottenlund, Denmark 55.

12. (1980) Danish Bilharziasis Laboratory (DBL). A practical guide to the identification of Fresh Water snails. Malacological Review 13: 95-119.

13. Liang YS, Bruce JI, Boyd DA (1987) Laboratory cultivation of schistosome. Proc Sino-Am. Symp 1: 34-48.

14. Chu KY, Dawood IK (1970) Seasonal abundance of trematode cercariae in Bulinus truncatus in a small focus of schistosomiasis in the Nile Delta. Bull World Health Organ 47: 420-422.

15. Omudu EA, lyough A (2005) Ecological studies of the gastropod fauna of some minor tributaries of River Benue in Makurdi, Nigeria. Animal Research International 2(2): 306 -310.

16. Okafor FC, Ngang I (2004) Freshwater snails of Niger-Cem, Nkalagu eastern Nigeria: Observations on some demographic aspect of the schistosome transmitting bulinids. Animal Research Institution 1: 120124.

17. Rabi SD (2017) Survey of freshwater snails on three parts of Jakara dam, Kano state, Nigeria. International Journal of Zoological Research 13(1): 20-25.

18. Diakité NR, Winkler MS, Coulibaly JT, Guindo-Coulibaly N, Utzinger J, et al. (2017) Dynamics of freshwater snails and Schistosoma infection prevalence in schoolchildren during the construction and operation of a multipurpose dam in central Côte d'Ivoire. Infectious Diseases of Poverty 6: 93.

19. Ejehu ZU, Ekwunife CA, Anumba JU, Onyido AE, Umeanaeto PU (2017) Snail fauna and investigations into the incidence of schistosoma infection in Lake of Oguta 1 Region, Imo State, Nigeria. Nigerian Journal of Parasitology 38(2): 173-178. 
ISSN: 2574-1241

DOI: 10.26717/BJSTR.2021.37.005963

Pam VA. Biomed J Sci \& Tech Res

(c) (P) This work is licensed under Creative BY Commons Attribution 4.0 License

Submission Link: https://biomedres.us/submit-manuscript.php

$\begin{array}{ll}\text { BIOMEDICAL } & \text { Assets of Publishing with us } \\ \text { RESEARCHES } & \text { - Global archiving of articles } \\ \text { - Immediate, unrestricted online access } & \text { - Rigorous Peer Review Process } \\ & \text { - Authors Retain Copyrights } \\ & \text { https://biomedres.us/ }\end{array}$

